\title{
EFFECT OF SODIUM CHLORIDE ON FAT OXIDATION IN THE PRESENCE OF HEME PIGMENTS
}

\author{
E.K.Tunieva ${ }^{1 *}$, A.A. Semenova ${ }^{1}$, A.N. Ivankin ${ }^{2}$, V.V. Nasonova ${ }^{1}$, A.N. Nikolaeva ${ }^{1}$ \\ ${ }^{1}$ V.M. Gorbatov Federal Research Center for Food Systems of Russian Academy of Sciences, 109316, Moscow, \\ Talalikhina str., 26, \\ ${ }^{2}$ Bauman Moscow State Technical University, Moscow, Russia \\ *e.tunieva@fncps.ru
}

https://doi.org/10.34302/2019.11.4.10

\begin{tabular}{ll}
\hline Article history: & ABSTRACT \\
Received: & The effects of salt on oxidative changes in fat and heme pigments were \\
29 April 2019 & evaluated. The back fat was salted with sodium chloride in the presence of \\
the hemoglobin. The indicators of the hydrolytic and oxidative spoilage were & investigated in the samples of back fat from White Large pigs at two years \\
Accepted: & of age. The proportions of heme and non-heme iron, as well as the content \\
29 November 2019 & of metmyoglobin were determined in the samples of \\
Keywords: & m. Longissimus dorsi from two-year-old female Large White pigs. Back fat \\
Back fat; & salting did not significantly affect the acid value of back fat. Addition of salt \\
Fatty acid composition; & in amounts of $3.5 \%$ and $5.0 \%$ initiated the oxidative changes. Addition of \\
Heme iron; & sodium chloride initiated fatty acid oxidation in the presence of the heme \\
Myoglobin; & pigments. The content of unsaturated acids decreased by \\
Salt & $22.8 \%$ when $5.0 \%$ of salt were added. The proportion of heme iron \\
& increased by $6.5 \%$ relative to free iron when $5.0 \%$ of sodium chloride were \\
added. The positive correlation between the metmyoglobin content and the \\
thiobarbituric acid value was found with the correlation coefficient of 0.98.
\end{tabular}

\section{Introduction}

For several decades, scientists have been studying the effect of meat salting on the oxidative changes. The data available from the scientific technical literature about the pro- and anti-oxidative effects of salt do not allow formulation of the unified view on the mechanism of the sodium chloride effect on fat oxidation. For example, according to some data, sodium chloride has the anti-oxidative effect (Andres et al., 2004) or does not influence the fat chemical properties (Calligaris and Nicoli, 2006). On the contrary, several researchers found the pro-oxidative effect of sodium chloride (Gheisari et al., 2010; Rhee and Ziprin, 2001; Jin et al., 2012). Sarraga et al. (2002) established that addition of sodium chloride inhibited the activity of the antioxidant enzyme, glutathione peroxidase, but on the other hand salting facilitated a decrease in the thiobarbituric acid value. There are data about interrelations between oxidation of lipids and myoglobin; oxidation of one of these components leads to formation of chemical compounds that can catalyze oxidation of another (Faustman et al., 2010; Min and Ahn, 2005; Min et al., 2010). Many hypotheses explain the chemistry of the oxidative processes under the impact of sodium chloride. Among the mare the action of the reactive chloride ion on lipids or modification of protein heme that catalyzes lipid oxidation (Ladikos and Lougovois, 1990), interaction of the heme iron ions with the chlorine ion, displacement of the iron ion from 
the protein macromolecule under an impact of the sodium ion (Zanardi et al., 2010), etc. Incoherence of data on the salt effect on the chemical changes in fats, apparently, can be explained by differences in selection of research samples, when different meat types with different content of heme pigments as well as different types and parameters of meat technological processing were mainly used. With this experiment setting, the number of factors influencing the processes of hydrolysis and oxidation upon salting significantly increases and can be a consequence of only indirect effect of sodium chloride on fats. It is worth noting that among these factors are the dose of sodium chloride, the presence of the heme pigments, heat treatment and so on (Jin et al., 2010; Cobos et al., 2008).

Despite different explanations of the mechanism of salt action on chemical changes in fats, the majority of researches link the prooxidative effect of sodium chloride with its impact on heme iron. Nevertheless, an iron type and a mechanism of its influence on the oxidative processes still leave many questions unanswered. Therefore, the aim of this study was to investigate the relationship between of the fat and heme pigments oxidation under the impact of sodium chloride.

\section{Materials and methods}

\subsection{Materials}

\subsubsection{Back fat samples}

The indicators of the hydrolytic and oxidative spoilage were determined in the samples of back fat from White Large pigs at two years of age. Taking into consideration the technological doses of sodium chloride in the recipes of sausages and products from meat, a range of sodium chloride concentrations from 2.0 to $5.0 \%$ was chosen for the experiment. For homogeneous salt distribution, back fat was minced in a grinder through a plate with a hole diameter of $2-3 \mathrm{~mm}$ and salted with salt in amounts of $0.0,2.0,3.5$ and $5.0 \%$ in the presence of the hemoglobin solution $(160 \mathrm{~g} / \mathrm{l})$ in an amount of $1.25 \%$ of back fat weight as this dose ensures the concentration of heme iron in back fat equal to the concentration of heme iron in myoglobin contained in $100 \mathrm{~g}$ of pork. After salting, back fat was vacuumed and cooked in a water bath at a temperature of $80^{\circ} \mathrm{C}$, then chilled and stored at a temperature of $4 \pm 2{ }^{\circ} \mathrm{C}$ for 3 days.

\subsubsection{Meat samples}

The proportions of heme and non-heme iron, as well as the content of metmyoglobin were determined in the samples of m. Longissimus dorsi from two-year-old female Large White pigs. Meat was minced in a grinder through a plate with a hole diameter of 2-3 $\mathrm{mm}$ and salted with table salt in amounts of 0.0,2.0, 3.5 and $5.0 \%$. The prepared samples were held at a temperature of $4 \pm 2^{\circ} \mathrm{C}$ for 24 hours, after which they were packed under vacuum and subjected to heat treatment until reaching a temperature of $72 \pm 2^{\circ} \mathrm{C}$.

\subsection{Methods}

The acid value was determined by the method based on titration of free fatty acids in the ether-alcohol solution of fat with the aqueous solution of alkaline. $20 \mathrm{~g}$ of the sample were ground in a mortar with $40 \mathrm{~g}$ of anhydrous sodium sulfate until smooth, the mixture was extracted for $5 \mathrm{~min}$ with $100 \mathrm{ml}$ of chloroform in a laboratory shaker, then filtered through a paper filter. $10 \mathrm{ml}$ of the filtrate was mixed with $10 \mathrm{ml}$ of ethanol and 2 drops of a $1 \%$ aqueousalcoholic solution of phenolphthalein and titrated with a $0.1 \mathrm{M}$ sodium hydroxide solution until a faint pink color was observed that was stable for $30 \mathrm{sec}$. The acid number $X, \mathrm{mg} \mathrm{KOH} /$ $\mathrm{g}$ of fat contained in the sample was calculated by the formula: $X=5.61 \cdot V \cdot K / m$, where $V$ is the volume of a $0.1 \mathrm{M}$ solution of potassium hydroxide used for titration, $\mathrm{ml} ; K$ is the correction factor to the potassium hydroxide solution; 5.61 - the amount of potassium hydroxide contained in $1 \mathrm{ml}$ of a $0.1 \mathrm{M}$ solution; $m$ is the mass of fat in the sample, determined gravimetrically in the filtrate, $\mathrm{g}$.

Peroxide value by the method based on oxidation of iodhydric acid with peroxides contained in fat with the following titration of 
released iodine with sodium thiosulphate. For this, $50 \mathrm{~g}$ of the sample were ground in a porcelain mortar with $100 \mathrm{~g}$ of anhydrous sodium sulfate to a homogeneous mass, extracted with $150 \mathrm{ml}$ of chloroform in a laboratory shaker for $5 \mathrm{~min}$ and filtered through a paper filter. $10 \mathrm{ml}$ of a fat-containing extract was mixed with $10 \mathrm{ml}$ of glacial acetic acid and $1 \mathrm{ml}$ of a $50 \%$ freshly prepared potassium iodide solution, the flask was immediately closed, the contents were stirred, and left for $5 \mathrm{~min}$ in a dark place at room temperature $22^{\circ} \mathrm{C}$. Then, $100 \mathrm{ml}$ of distilled water was poured into the flask, thoroughly mixed, $1 \mathrm{ml}$ of a $1 \%$ starch solution was added. The liberated iodine was titrated with a $0.01 \mathrm{M}$ sodium thiosulfate solution until a milky white color, stable for $5 \mathrm{~s}$. The peroxide value $X, \mathrm{mmol}$ of active oxygen / $\mathrm{kg}$ of fat $\left(\mathrm{mmol} \mathrm{O}_{2} / \mathrm{kg}\right)$ contained in the sample, was calculated by the formula $X=\left(V_{1}-V_{2}\right) \cdot C$. $K \cdot 1000 / m$, where $V_{1}$ is the volume of sodium thiosulfate solution used in the analysis, $\mathrm{ml} ; V_{2}$ is the volume of sodium thiosulfate solution used in the control determination, $\mathrm{ml} ; C$ is the concentration of the used sodium thiosulfate solution, $\mathrm{mol} / \mathrm{L} ; K$ is the correction factor for the titer of sodium thiosulfate solution; 1000 coefficient taking into account the conversion of the measurement result in $\mathrm{mmol} / \mathrm{kg} ; m$ is the mass of a portion of fat, determined gravimetrically in the extract, $\mathrm{g}$.

Determination of the thiobarbituric acid value was carried out by the method based on the development of stained substances as a result of interaction of fat oxidation products with 2thiobarbituric acid and measurement of the color intensity on a spectrophotometer (Zhuravskaya et al., 1985). $50 \mathrm{~g}$ of the sample were homogenized with $50 \mathrm{ml}$ of distilled water, 47.5 $\mathrm{ml}$ of water and $2.5 \mathrm{ml}$ of a $3 \mathrm{M}$ hydrochloric acid solution were added, the mixture was placed in a distillation apparatus, and distillation was distilled off to collect $50 \mathrm{ml}$ of distillate. 5 $\mathrm{ml}$ of the obtained distillate was mixed with $5 \mathrm{ml}$ of a $0.02 \mathrm{M}$ solution of thiobarbituric acid and kept for 35 minutes at a temperature of $100^{\circ} \mathrm{C}$. In parallel, control was carried out with $5 \mathrm{ml}$ of distilled water instead of distillate. The solutions were cooled for $10 \mathrm{~min}$ to a temperature of $25{ }^{\circ} \mathrm{C}$ and the absorbance was measured at a wavelength of $535 \pm 10 \mathrm{~nm}$. Thiobarbituric number $X, \mathrm{mg}$ malondialdehyde per $\mathrm{kg}$ of product, was calculated by the formula: $X=D$. 7.8 , where $D$ is the optical density of the solution; 7.8 - empirical coefficient.

The fatty acid composition was determined using a flame ionization detector by the method of gas chromatography (Ivankin et al., 2016). For this, a 10-g weighed portion of a sample was treated for 3-24 h with a mixture of $10 \mathrm{~mL}$ of chloroform and $10 \mathrm{~mL}$ of methanol by the modified Folch method in the presence of a $1 \%$ $\mathrm{KCl}$ solution to dissolve the lipid component; the extract was filtered through paper and evaporated to dryness. Then, $0.01 \mathrm{~g}$ of the residue was mixed with $3 \mathrm{~mL}$ of a $15 \%$ solution of acetyl chloride in methanol; the mixture was incubated for $2 \mathrm{~h}$ at $100^{\circ} \mathrm{C}$; and the $\mathrm{pH}$ of the mixture was adjusted to $5.0-6.0$ by adding a potassium hydroxide solution in methanol. Three milliliters of a saturated $\mathrm{NaCl}$ aqueous solution and $3 \mathrm{~mL}$ of hexane were added to the resulting mixture. The solution was allowed to stand for several minutes, and $0.2 \mathrm{~mL}$ of the clear hexane layer containing fatty acid methylesters was sampled for analysis. The fatty acid composition was determined using a 7890A gas chromatograph with a HP-Innowax capillary column $(0.2 \mathrm{~mm}$ in diameter, $30 \mathrm{~m}$ in length, and with the thickness of the stationary phase layer of $0.33 \mu \mathrm{m})$ and a flame ionization detector (FID). Conditions of chromatography using a HP-Innowax capillary column with a FID: the temperature in the column oven was increased from 100 to $260{ }^{\circ} \mathrm{C}$ at a rate of $10^{\circ} / \mathrm{min}$; the injector temperature was $250{ }^{\circ} \mathrm{C}$; and the detector temperature was $300^{\circ} \mathrm{C}$. Nitrogen was used as a carrier gas with the flow rate of 20 $\mathrm{mL} / \mathrm{min}$; the hydrogen flow rate was $35 \mathrm{~mL} / \mathrm{min}$; the injection sample volume was $1 \mu \mathrm{L}$; and the split flow ratio was $1: 100$. The total analysis time was $30 \mathrm{~min}$. The amount of an analyte was assessed by comparing its peak area with the peak area of an internal standard. Calculation of the content of individual fatty acids according to 
an automatic program, taking into account graduation by standard substances.

Determination of iron in the samples was carried out by acid mineralization under pressure using $10 \mathrm{ml} \mathrm{HNO}_{3}$ in the MARS 6 system. After mineralization, the solutions are transferred to a $50 \mathrm{ml}$ flask and brought to the mark with distilled water. Analytical determination of iron concentration was carried out on the atomic absorption spectrophotometer with electrothermal atomization Agilent 280Z. Measurements were carried out using hollow cathode lamps at a wavelength of $248.3 \mathrm{~nm}$, slit width $0.2 \mathrm{~nm}$, with background correction. The measurement parameters were selected according to the specified parameters of the equipment used.

Heme iron was determined by the acidified acetone extraction method (Hornsey, 1956) with modifications. Meat (5 g) was transferred to a $50 \mathrm{ml}$ Polypropylene centrifuge tube and $10.0 \mathrm{ml}$ of acidified acetone $(95.7 \%$ acetone; $2.4 \% \mathrm{HCl}$ ) was added. The suspension was homogenized for $30 \mathrm{~S}$ at $13.500 \mathrm{rpm}$ using Ultra Turrax T25, which was then washed 3 times with $3.0 \mathrm{ml}$ of acidified acetone. The final concentration in the soluble phase of the suspension was $80 \%$ acetone and $2.0 \% \mathrm{HCl}$. The suspension was quickly stirred and kept on ice for 1 hour. Insoluble substances were previously precipitated by centrifugation (1 hour, $0{ }^{\circ} \mathrm{C}, 10000 \mathrm{~g}$ ) and $5 \mathrm{ml}$ of supernatant was filtered through a Minisart RC 15 filter. The filtrate absorption was measured at $640 \mathrm{~nm}$ and the iron heme content was calculated. All filtered samples were visually checked for turbidity before measurement. The turbid samples were filtered again before measurement.

Absorption spectra of MetMb, DeoMb and $\mathrm{OxyMb}$ solutions were obtained using a Varian Cary Bio-50 spectrophotometer (USA) with a $1 \mathrm{~cm}$ path length cuvette from $650 \mathrm{~nm}$ to $475 \mathrm{~nm}$.

\subsection{Statistical analysis}

Each experiment was carried out in three replic ations. Data are reported as mean values with standard deviation. The statistical significance of differences between indicators was assessed using the Student's t-test.P values less than 0.05 were considered statistically significant.

\section{Results anddiscussions}

\subsection{Fat hydrolysis and oxidation}

Meat and meat products are a complex multi-component system, which significantly complicates acquisition of reliable data about an effect of sodium chloride on fat oxidation in the presence of many biochemical compounds of animal raw materials and different technological factors, among which are the heme pigments and temperature factor, which can affect the antiand pro-oxidative activity of salt. In this connection, the indicators of the hydrolytic and oxidative spoilage of salted back fat in the absence and presence of the heme pigments after heat treatment were studied.

Addition of table salt in the presence of heme pigments did not significantly influence the hydrolytic changes in back fat - the acid value ( $p>0.05)$ (Fig. 1). Back fat salting with sodium chloride in an amount of $3.5 \%$ facilitated an increase in the peroxide value by $37.6 \%(p<0.05)$, the further increase in the salt dose up to $5.0 \%$ initiated the growth of the peroxide value by $73.2 \%(\mathrm{p}<0.05)$ compared to unsalted back fat (Fig. 2). The similar trend was observed in the measurement of the thiobarbituric acid value. Addition of sodium chloride in amounts of $3.5 \%$ and $5.0 \%$ led to an increase in the thiobarbituric acid value by 43.9 $\%(\mathrm{p}<0.05)$ and $80.7 \%(\mathrm{p}<0.05)$, respectively (Fig. 3). 


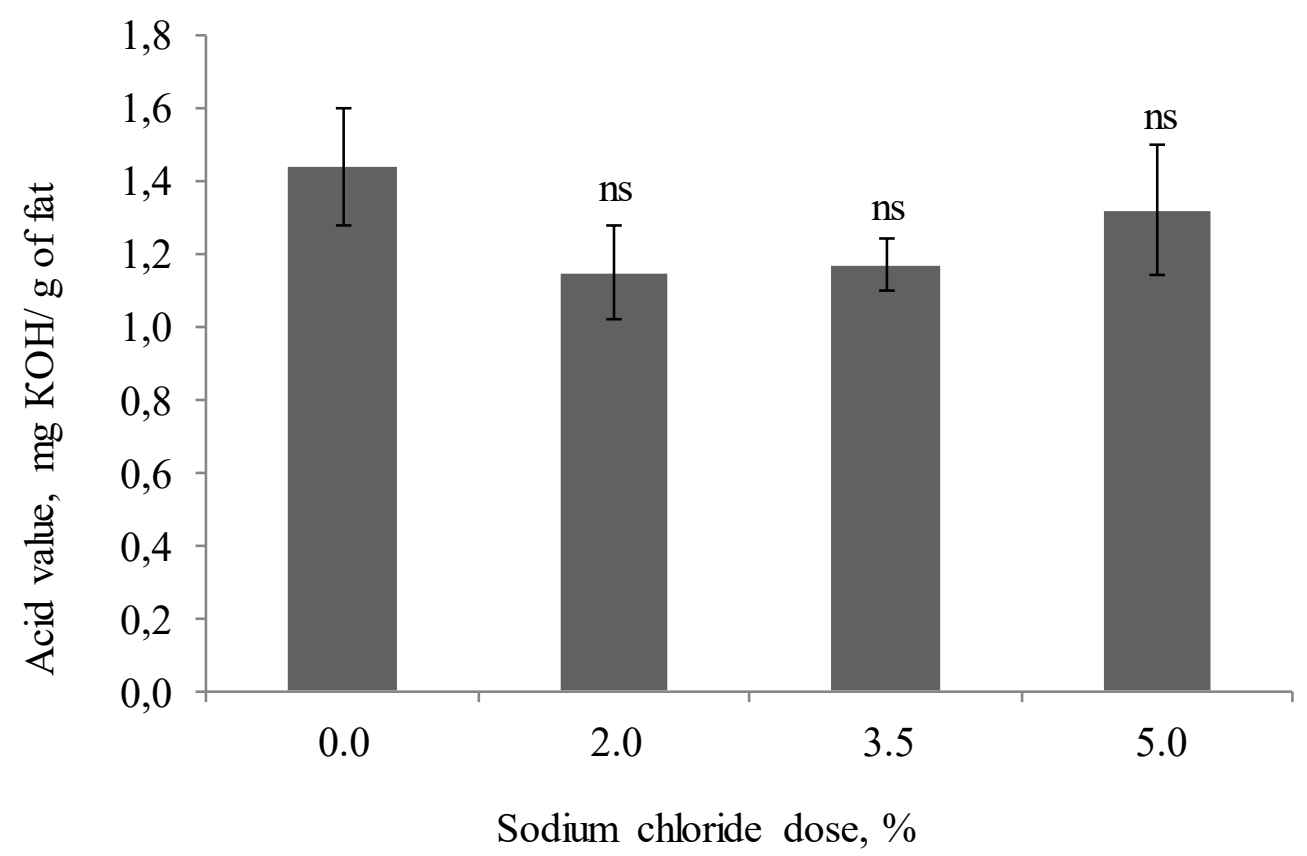

Figure 1. Effect of sodium chloride on the acid value in back fat in the presence of heme pigments ${ }^{n s}$ not significant at $\mathrm{p} \geq 0.05$ in comparison with unsalted sample.

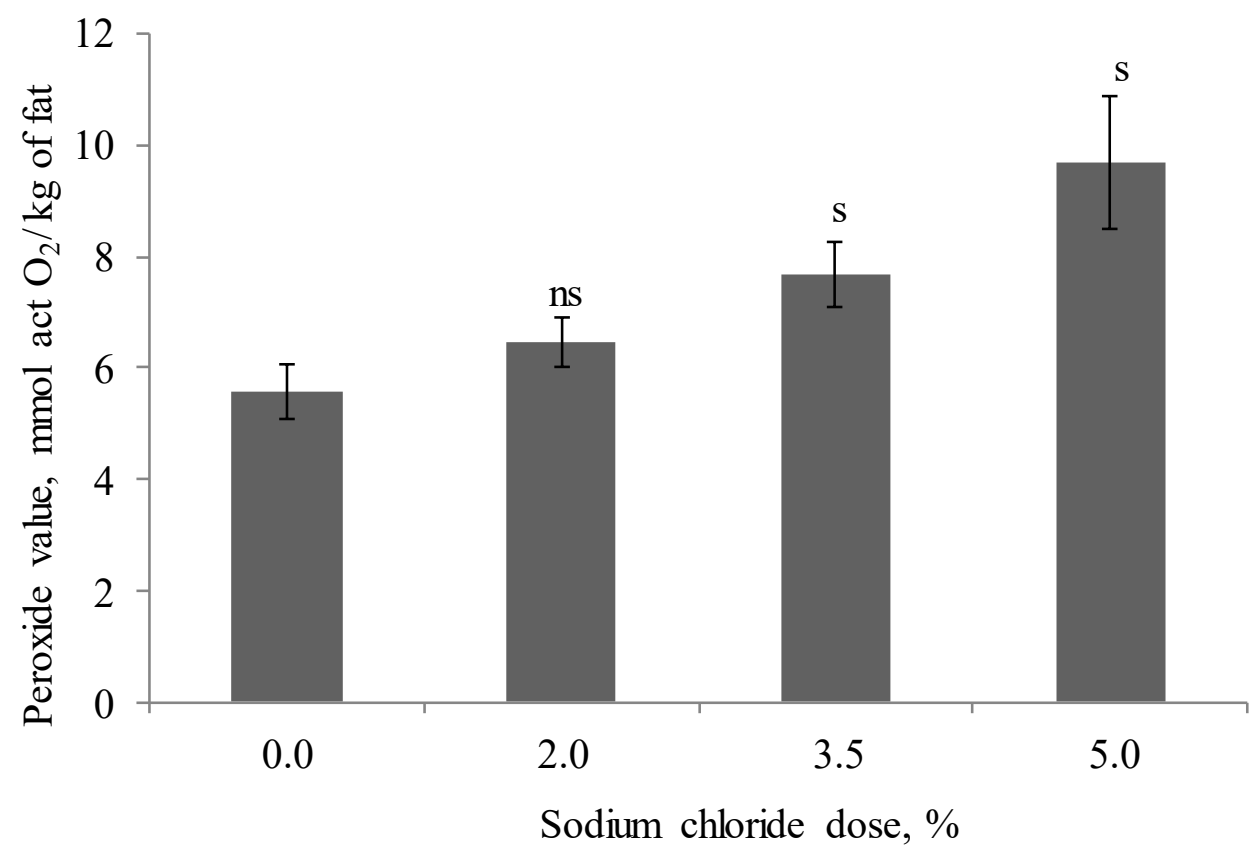

Figure 2. Effect of sodium chloride on the peroxide value in back fat in the presence of heme pigments

${ }^{\mathrm{ns}}$ not significant at $\mathrm{p} \geq 0.05 ;{ }^{\mathrm{s}}$ significant at $\mathrm{p}<0.05$ in comparison with unsalted sample. 


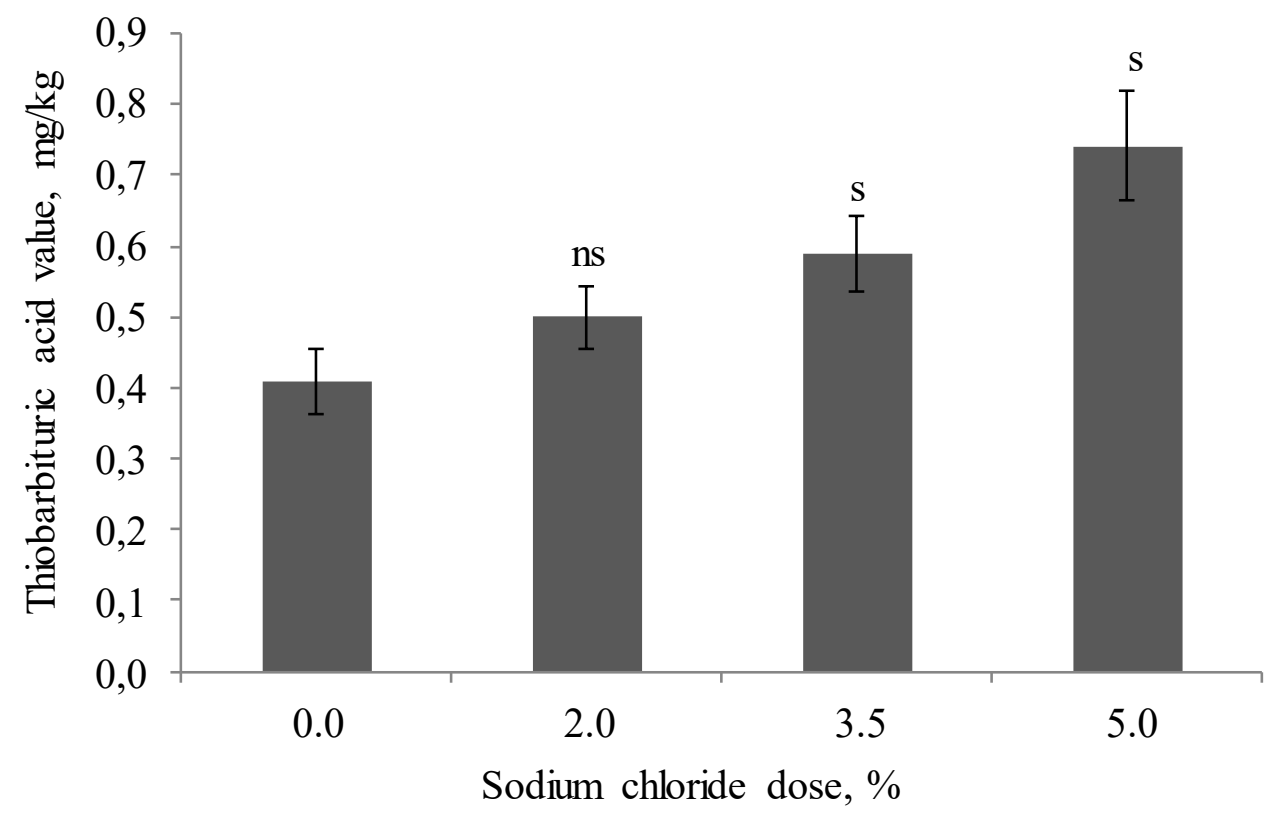

Figure 3. Effect of sodium chloride on the thiobarbituric acid value in back fat in the presence of heme pigments

${ }^{\mathrm{ns}}$ not significant at $\mathrm{p} \geq 0.05$; ${ }^{\mathrm{s}}$ significant at $\mathrm{p}<0.05$ in comparison with unsalted sample.

The studies on the effect of different salt doses on back fat oxidation in the absence of hemoglobin demonstrated that addition of salt into the back fat composition did not result in an increase in the indicators of the hydrolytic and oxidative spoilage. On the contrary, addition of $2.0 \%$ of salt caused a decrease in the oxidation product (Tunieva et al., 2017). The antioxidative effect of small doses of salt can be explained by an effect of sodium chloride on a decrease in the water activity, which retards fat oxidation, and by the absence of the heme pigments in back fat. Compared to these data, the presence of heme initiated the oxidative changes in unsalted back fat by 2.2 times $(p<0.05)$ for the peroxide value and 1.5 times $(\mathrm{p}<0.05)$ for the thiobarbituric acid value.

Therefore, the presence of the heme pigments changes the character of the table salt effect on lipid oxidation initiating chemical changes in fat in the presence of sodium chloride. The obtained data correspond to the results of the study on the volatiles composition of salted back fat, which suggest that in the presence of the heme pigments, addition of even small amounts of sodium chloride (2.0\%) initiates the oxidative processes compared to unsalted back fat (Tunieva and Ivankin, 2015).

Addition of table salt in the presence of heme pigments did not significantly influence the hydrolytic changes in back fat - the acid value $(p>0.05)$. Back fat salting with sodium chloride in an amount of $3.5 \%$ facilitated an increase in the peroxide value by $37.6 \%$ $(p<0.05)$, the further increase in the salt dose up to $5.0 \%$ initiated the growth of the peroxide value by $73.2 \%(p<0.05)$ compared to unsalted back fat. The similar trend was observed in the measurement of the thiobarbituric acid value. Addition of sodium chloride in amounts of $3.5 \%$ and $5.0 \%$ led to an increase in the thiobarbituric acid value by $43.9 \%(\mathrm{p}<0.05)$ and $80.7 \%(\mathrm{p}<0.05)$, respectively.

The studies on the effect of different salt doses on back fat oxidation in the absence of hemoglobin demonstrated that addition of salt into the back fat composition did not result in an increase in the indicators of the hydrolytic and oxidative spoilage. On the contrary, addition of $2.0 \%$ ofsalt caused a decrease in the oxidation 
product (Tunieva et al., 2017). The antioxidative effect of small doses of salt can be explained by an effect of sodium chloride on a decrease in the water activity, which retards fat oxidation, and by the absence of the heme pigments in back fat. Compared to these data, the presence of heme initiated the oxidative changes in unsalted back fat by 2.2 times $(p<0.05)$ for the peroxide value and 1.5 times $(\mathrm{p}<0.05)$ for the thiobarbituric acid value.

Therefore, the presence of the heme pigments changes the character of the salt effect on lipid oxidation initiating chemical changes in fat in the presence of sodium chloride. The obtained data correspond to the results of the study on the volatiles composition of salted back fat, which suggest that in the presence of the heme pigments, addition of even small amounts of sodium chloride $(2,0 \%)$ initiates the oxidative processes compared to unsalted back fat (Tunieva and Ivankin, 2015).

\subsection{Fatty acid composition}

Back fat salting did not significantly influence the changes in the fatty acid composition in the absence of heme pigments $(p>0.05)$. Addition of the hemoglobin solution led to changes in the character of the table salt effect on the fatty acid composition of back fat after heat treatment (Fig. 4). Addition of sodium chloride initiated oxidation of fatty acids. The quantity of unsaturated acids in the sample salted with $5.0 \%$ of table salt decreased by 22.8 $\%$ relative to their content in the sample of unsalted back fat $(\mathrm{p}<0.05)$.

Therefore, the presence of the heme pigments initiated the oxidative changes in lipids during salting. The acceleration of the oxidative processes in the presence of salt is a consequence of the indirect pro-oxidative effect of sodium chloride linked with its impact on the heme pigments.

\subsection{Heme and non-heme iron}

To establish the mechanism of the heme pigment involvement in the development of the oxidative processes within the framework of the experiment, an effect of salt on the ratio of heme and non-heme iron was studied. The available data on the salt effect on the heme pigments during heat treatment are ambiguous. For example, the research of Kristensen and Purslow (2001) indicates an increase in the proportion of heme iron relative to free iron during heat treatment in the pork samples salted with sodium chloride. It is necessary to note that this positive trend was established only for heat treated salted meat as the studies on the effect of table salt on the meat heme pigments before cooking indicated the absence of significant differences in the content of heme and non-heme iron. On the contrary, Min et al. (2010) found that addition of sodium chloride to meat products from beef led to degradation of myoglobin, which facilitated an increase in the concentration of free iron in meat.

The results of our studies on determination of heme and non-heme iron indicate an increase in the proportion of heme iron relative to free iron by $6.5 \%$ as a result of salting upon addition of sodium chloride in an amount of $5.0 \%(\mathrm{p}<0.05) \quad($ Fig. 5).It is obvious that addition of sodium chloride stabilizes the heme pigments and prevents their destruction during heat treatment. Therefore, the negative correlation between heat denaturation of the heme pigments and oxidative changes was found. This effect can be explained differently: the lower catalyzing effect of free iron compared to heme iron and a role played by a form of iron oxidation, not by an iron type. The obtained results correspond to the study of Johns et al. (1989) who established that heme iron had a greater pro-oxidative effect compared to free iron.

Several studies give evidence of the relationship of heme and non-heme iron with fat oxidation. Rhee and Ziprin (1987) found that the heme iron concentration was more significant than an amount of non-heme iron when predicting lipid oxidation in meat. Other studies (Baron and Andersen, 2002; Tichivangana and Morrissey, 1985) demonstrated the stronger catalyzing effect of non-heme iron on meat product oxidation compared to heme iron. 
Taking into consideration such ambiguous results of available studies and the fact that heme iron can also be present in the oxidized forms of myoglobin, we studied the changes in the proportion of metmyoglobin relative to the total content of the heme pigments depending on addition of sodium chloride (Fig.6).

The results showed that the ratio of metmyoglobin to the total content of the myoglobin forms increased with an increase in the salt dose. Therefore, the positive correlation was established between the metmyoglobin content and the thiobarbituric acid value (correlation coefficient $0.98 \%$ ). The obtained results are consistent with other studies that established the relationship between oxidation of myoglobin and meat lipids (Rhee and Ziprin, 2001; Andersen and Skibsted, 1991; Yin and Faustman, 1993).

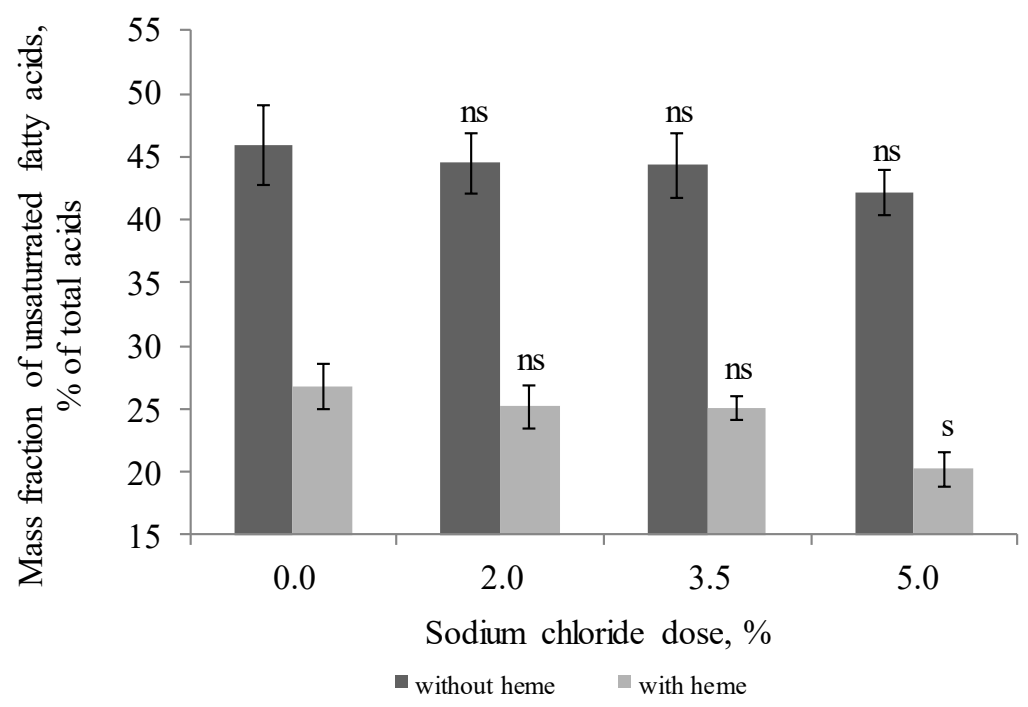

Figure 4. Dynamics of changes in the mass fraction of unsaturated fatty acids in back fat depending on the sodium chloride concentration

Averages in the same line do not differ significantly (ns) at $\mathrm{p} \geq 0.05$ or differ (s) at $\mathrm{p}<0.05$ from unsalted sample.

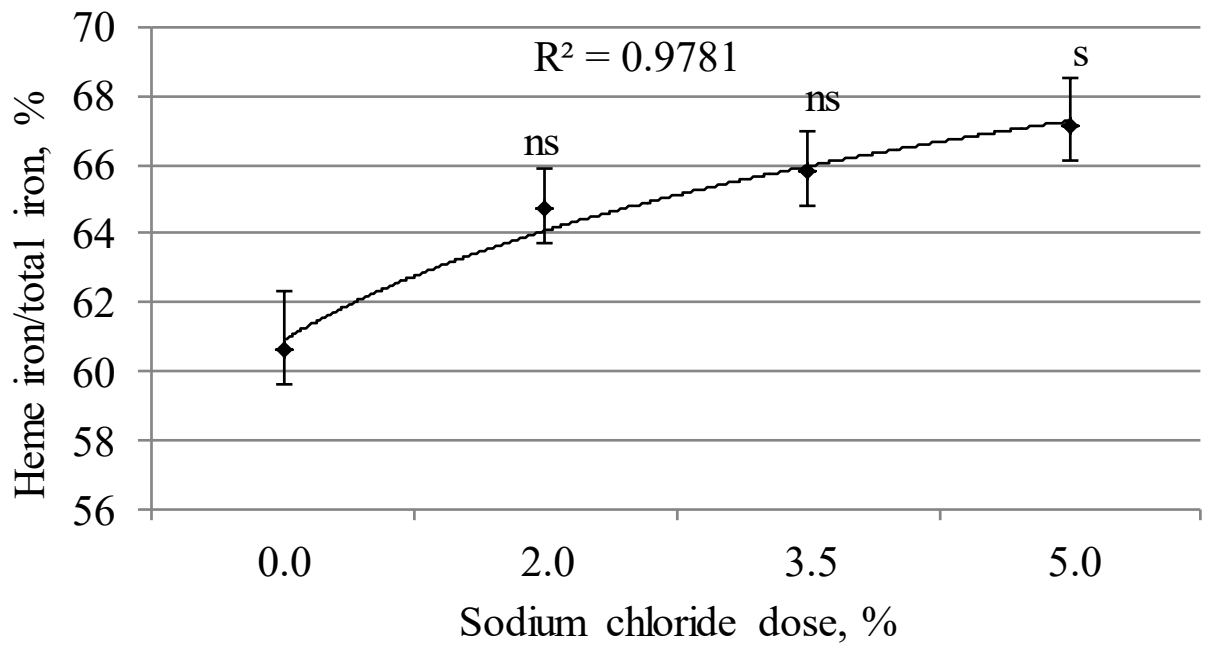

Figure 5. Changes in the proportion of heme iron relative to total iron depending on the sodium chloride concentration 
${ }^{\mathrm{ns}}$ not significant at $\mathrm{p} \geq 0.05$; ${ }^{\mathrm{s}}$ significant at $\mathrm{p}<0.05$ in comparison with unsalted sample

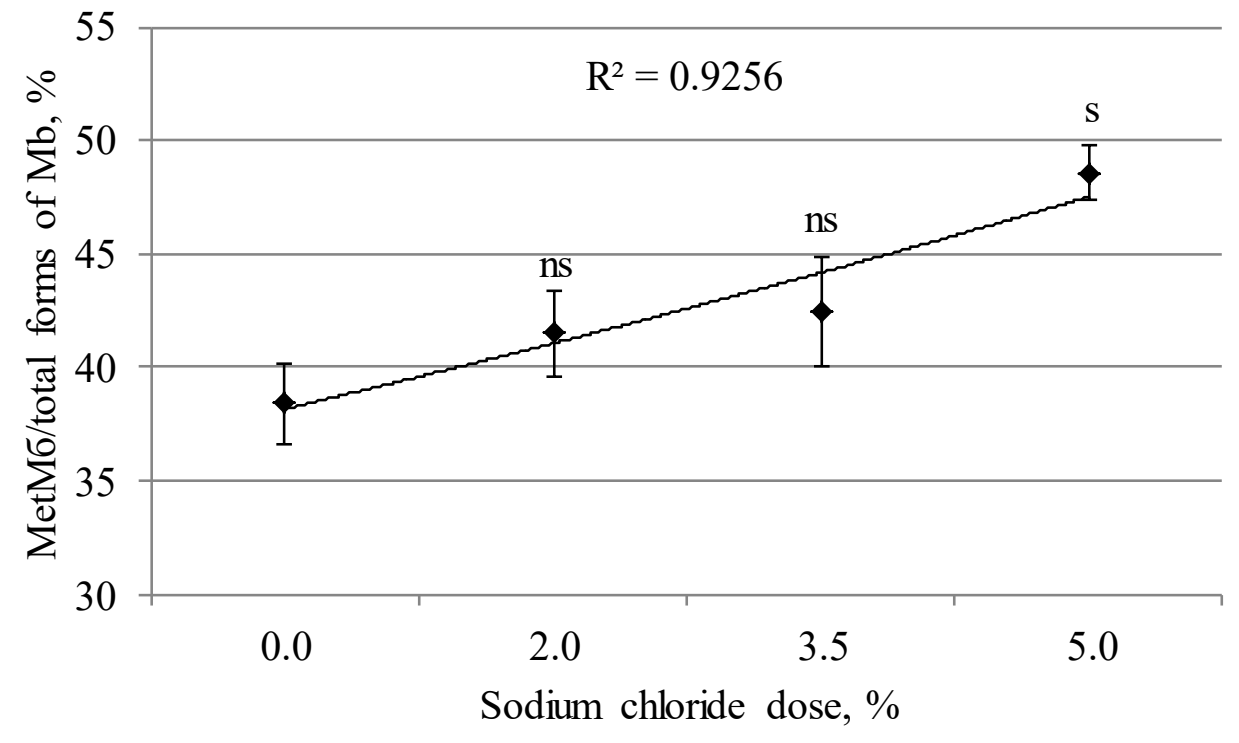

Figure 6. Changes in the myoglobin content depending on the sodium chloride concentration (Mb - myoglobin)

${ }^{n s}$ not significant at $\mathrm{p} \geq 0.05 ;{ }^{\mathrm{s}}$ significant at $\mathrm{p}<0.05$ in comparison with unsalted sample.

\section{Conclusions}

The results of the study make a contribution to substantiation of the sodium chloride effect on the oxidative changes. It was established that addition of sodium chloride increased the heme pigment stability to high temperature and concurrently initiated the oxidative changes in lipids. In this connection, it was suggested that heme iron had the higher catalyzing effect on fat oxidation compared to free iron. The obtained effect can be explained by the salt impact on the development of the myoglobin oxidized forms, which catalyzed lipid oxidation.

\section{References}

Andersen, H.J., Skibsted, L.H. (1991). Oxidative stability of frozen pork patties. Effect of light and added salt.Journal of Food Science, 56, $1182-4$.

Andres, A.I., Cava, R., Ventanas, J., Muriel, E., Ruiz, J. (2004). Lipid oxidative changes throughout the ripening of drycured Iberian hams with different salt contents and processing conditions. Food Chemistry, 84, 375-81.
Baron, C.P., Andersen, H.J. (2002). Myoglobininduced lipid oxidation. A review. Journal of Agricultural and Food Chemistry, 50, 3887-3897.

Calligaris, S,Nicoli, Mc. (2006). Effect of selected ions from lyotropic series on lipid oxidation rate. Food Chemistry, 94, 130-4.

Cobos, A.,Veiga, A., Diaz, O. (2008). Chemical and lipid composition of deboned pieces of dry-cured pork forelegs as affected by desalting and boiling: The effects of vacuum packaging. Food Chemistry, 106, 951-6.

Faustman, C., Sun, Q., Mancini, R., Suman, S.P. (2010). Myoglobin and lipid oxidation interactions: Mechanistic bases and control. Meat Science, 86, 86-94.

Gheisari, H.R., Moller, J.K.S., Adams, C.E., Skibsted, L.H. (2010). Sodium Chloride or Heme Protein Induced Lipid Oxidation in Raw, Minced Chicken Meat and Beef. Czech Journal of Food Sciences, 28, 36475.

Jin, G., He, L., Zhang, J., Yu, X., Wang, J., Huang, F. (2012).Effects of temperature and $\mathrm{NaCl}$ percentage on lipid oxidation in 
pork muscle and exploration of the controlling method using response surface methodology (RSM).Food Chemistry,131, 817-25.

Jin, G., Zhang, J., Yu, X., Lei, Y., Wang, J. (2010). Lipolysis and lipid oxidation in bacon during curing and drying-ripening. Food Chemistry, 123, 465-71.

Johns, A.M., Birkinshaw, L.H., Ledward, D.A. (1989). Catalysts of lipid oxidation in meat products. Meat Science, 25, 209-20.

Hornsey, H.C. (1956). The color of cooked cured pork. I. Estimation of the nitric oxidehaem pigments. Journal of the Science of Food and Agriculture, 7, 534-540.

Ivankin, A.N., Oliferenko, G.L., Kulikovskii, A.V., Chernukha, I.M., Semenova, A.A., Spiridonov, K.I., Nasonova, V.V. (2016). Determination of unsaturated fatty acids with a migrating double bond in complex biological matrices by gas chromatography with flame ionization and mass spectrometry detection. Journal of Analytical Chemistry, 71(11), 1131-7.

Kristensen, L., Purslow, P.P. (2001). The effect of processing temperature and addition of mono- and di-valent salts on the hemenonheme-iron ratio in meat. Food Chemistry, 73, 433-9.

Ladikos, D., Lougovois, V. (1990). Lipid Oxidation in Muscle Foods - a Review. Food Chemistry, 35, 295-314.

Min, B., Ahn, D.U. (2005). Mechanism of lipid peroxidation in meat and meat products - a review. Food Science and Biotechnology, 14, 152-63.

Min, B., Cordray, J.C., Ahn, D.U. (2010). Effect of $\mathrm{NaCl}$, myoglobin, $\mathrm{Fe}(\mathrm{II})$, and $\mathrm{Fe}(\mathrm{III})$ on lipid oxidation of raw and cooked chicken breast and beef loin. Journal of Agricultural and FoodChemistry, 58, 6005.

Rhee, K.I., Ziprin, Y.A. (1987). Lipid oxidation in retail beef, pork and chicken muscles as affected by concentrations of heme pigments and non-heme iron and microsomal enzymic lipid peroxidation activity. Journal of Food Biochemistry, 11, $1-15$.

Rhee, K.S., Ziprin, Y.A. (2001). Pro-oxidative effects of $\mathrm{NaCl}$ in microbial growthcontrolled and uncontrolled beef and chicken. Meat Science, 57, 105-12.

Sarraga, C., Carreras, I., Garcia Regueiro, J.A. (2002). Influence of meat quality and $\mathrm{NaCl}$ percentage on glutathione peroxidase activity and values for acid-reactive substances of raw and dry-cured Longissimus dorsi. Meat Science, 62, 5037.

Tichivangana, J.Z., Morrissey, P.A. (1985). Metmyoglobin and inorganic metals as prooxidants in raw and cooked muscle systems. Meat Science, 15, 107-16.

Tunieva, E.K., Nasonova, V.V., Stanovova, I.A., Spiridonov, K.I., Kurzova, A.A. (2017). Effect of salting on back fat hydrolysis and oxidation, IOP Conf. Series: Earth and Environmental Science, 85, 012047.

Tunieva, E.K., Ivankin, A.N. (2015). Influence of sodium chloride on the composition of volatile substances formed during the oxidation of lard. Vsyo o myase, 2, 27-30.

Yin, M.C., Faustman, C. (1993). The influence of temperature, $\mathrm{pH}$ and phospholipid composition upon the stability of myoglobin and phospholipids: A liposome model. Journal of Agricultural and Food Chemistry, 41, 853-7.

Zanardi, E., Ghidini, S., Conter, M., Lanieri, A. (2010). Mineral composition of Italian salami and effect of $\mathrm{NaCl}$ partial replacement on compositional, physicochemical and sensory parameters. Meat Science, 86, 742-7.

Zhuravskaya, N. C., Alekhina, L. T., Otryashenkova, L. M. (1985). Research and quality control of meat and meat products. Agropromizdat, Moscow, 79-82. 